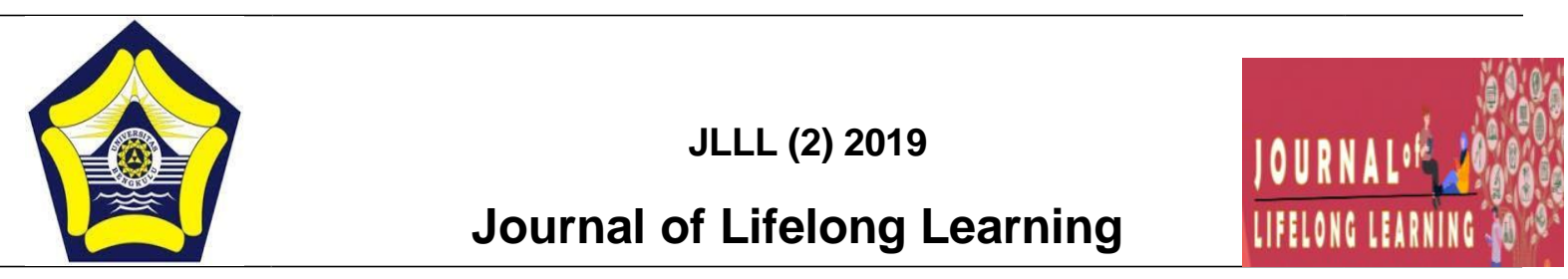

\title{
PENGAWASAN KOPERASI USAHA EKONOMI DESA SIMPAN PINJAM (UED-SP)
}

\author{
Yeni Anggraini, Wahiruddin Wadin², Suardi Jasma ${ }^{3}$ \\ ${ }^{1}$ Nonformal Education, University of Bengkulu, Indonesia, yenianggaraini@gmail.com \\ ${ }^{2}$ Nonformal Education, University of Bengkulu, Indonesia, wahiruddinwadin@gmail.com \\ ${ }^{3}$ Nonformal Education, University of Bengkulu, Indonesia, suardijasma@gmail.com
}

\begin{abstract}
The general objective of this study was to examine the cooperative supervision of the savings and loan village economic business (UED-SP) Talang Pauh Jaya. The method used in this research is qualitative which objectively describes the supervision of cooperatives of the savings and loan village economic business (UED-SP) Talang Pauh Jaya in Talang Pauh Village, Pondok Kelapa District, Bengkulu Tengah Regency. with data collection techniques namely interviews, observation, and documentation. The research subjects were the Chairperson of UED-SP Talang Pauh Jaya (Mr. Yanap), Secretary of the UED-SP Talang Pauh Jaya (Mr. Suprayitno) and Treasurer of the UED-SP Talang Pauh Jaya (MrArdiansyah). To prove the magnitude of the data, data was checked using triangulation techniques, time triangulation and subject triangulation. Data is analyzed through stages namely data reduction, data presentation, and conclusion drawing. From the results of the study found results, namely: First, there is the planning of the work of the Talang Pauh Jaya UED-SP, which was previously agreed upon. Second There are irregularities / problems in the UED-SP cooperative Talng Pauh Jaya. Third, there is a form of control over irregularities / problems that occur at UED-SP Talang Pauh Jaya.
\end{abstract}

Keywords: Job planning, irregularities, problems, forms of controlling irregularities

(C) 2019 Dept of Nonformal Education UNIB

Address correspondence:

e-ISSN

JI. W.R. Supratman, Kandang Limun, Muara Bangka Hulu,

Kota Bengkulu, Bengkulu 38371 


\section{PENDAHULUAN}

Koperasi UED-SP Talang Pauh Jaya berdiri pada tahun 2002, awal berdirinya koperasi ini karena adanya bantuan dana desa dari pemerintah yakni BANDES (Bantuan Desa). Modal awal koperasi ini RP. 6.000.000 yang pada awalnya beranggota 40 orang, Koperasi UED-SP Talang Pauh Jaya merupakan salah satu koperasi berbadan hukum, yang bertujuan untuk meningkatkan taraf hidup para anggotanya. Kegiatan Koperasi UED-SP Talang Pauh Jaya ini bergerak dibidang simpan pinjam. Besar pinjaman anggota diberikan secara berjenjang, naik sesuai dengan ketentuan yang berlaku. Permodalan berasal dari modal sendiri. Koperasi ini dirasakan banyak manfaatnya bagi anggota terkhususnya masyarakat Talang Pauh itu sendiri, karna koperasi dibangun dan dikembangkan sesuai dengan nilai, prinsip dan dasar-dasar penumbuhan dan serta pengembangan koperasi.

Jumlah anggota pada UED-SP Talang Pauh Jaya ini mengalami peningkatan yang berguyur, pada tahun 2016 mencapai 111 orang, 2017 mencapai 197 orang , 2018 pada sekarang ini mencapai 287 orang. dengan modal yang sudah mencapai Rp 400.000.000,. Sistem pengembalian pinjaman yaitu sipeminjam menyicil pinjaman setiap bulan dengan jumlah yang telah disepakati bersama, dengan bunga $2 \%$, dan jika telah melewati tanggal maka harus membayar denda sebesar Rp.10.000 . Jika tidak dilunasi dalam jangka waktu, maka ada petugas yang memberikan peringatan, jika belum juga dilunasi maka jaminan yang diberikan pada waktu peminjaman terpaksa harus disita, Jaminan ini biasanya berupa BPKB,SKT, dan lain sebagainya. Tingkat kemacetan pada kopersrasi ini sangat kecil paling tinggi $15 \%$. Besarnya pinjaman awal sebesar Rp.500 000. dan lama kelamaan akan naik jika kita lancar membayar atau dilihat dari kemampuan si peminjam, karena yang boleh meminjam uang koperasi ini hanyalah warga Talang Pauh itu sendiri. Prinsip-prinsip koperasi pada umumnya harus diterapkan atau dilaksanakan pada setiap koperasi, tidak banyak koperasi yang menerapkan dan melaksanakan prinsip koperasi dengan baik dan benar.

Menurut Hadi Purwanto (2008), yaitu : sanggar kegiatan belajar adalah suatu tempat atau sarana yang digunakan oleh suatu pelatihan atau sekumpulan orang untuk melakukan suatu kegiatan. sangat jarang ditemukan disuatu desa, usaha koperasi simpan pinjam yang berjalan aktif bahkan dari tahun ke tahunnya mengalami perkembangan. Banyak kita jumpai koperasi dipedesaan itu umurnya hanya sebentar saja yakni' tidak berjalan lama', apa lagi seperti UEDSP Talang Pauh Jaya ini, yang modal awalnya dari bantuan desa. Oleh karena itu peneliti sangat tertarik dan ingin mengetahui bagaimana Pengawasan di koperasi UED-SP Talang Pauh Jaya ini, karena pengelolaan dan pengawasan yang bagus membuat koperasi ini terus berjalan maju dari tahun ke tahunnya.

\section{METODE}

Dalam penelitian ini diarahkan pada upaya menemukan teori-teori yang bersifat kualitatif deskriftif karena permasalahan yang ada dalam penelitian ini tidak berkenaan dengan angkaangka, tetapi menguraikan,menggambarkan dan menelaah suatu kasus secara lebih rinci dan detail tentang pengawasan koperasi usaha ekonomi desa simpan pinjam (ued-sp) talang pauh jaya didesa talang pauh kecamatan pondok kelapa kabupaten bengkulu tengah. Dalam penelitan 
ni, digunakan kualitatif deskriftif . sebagai instrument utama dalam penelitian kualitatif, peneliti berpartisipasi secara tidak langsung hanya menganalisa, mewawancarai, mengobservasi, langkahnya yaitu menganalisa data yang ada.

\section{HASIL DAN PEMBAHASAN}

Pelaksaan pekerjaan di UED-SP Talang Pauh Jaya ini sesuai dengan perencanaan yang telah disepakati bersama sebelumnya, didalam pelaksanaan pekerjaan terdapat beberapa macam penyimpangan pekerjaan, karena adanya pengawasan yang baik tentunya ada pengendalian terhadap penyimpangan tersebut. Pengawasan koperasi UED-SP Talang Pauh Jaya yaitu: pengawasan dalam mempersiapkan kemajuan suatu koperasi itu sendiri.

1. Keanggotaan arus bersikap sukarela dan terbuka, sukarela yang dimaksud yakni tidak hanya menjalankan tugas masing-masing saja tapi mempunyai rasa kerjasma yang tinggi, dan terbuka adalah masing-masing orang saling membantu dalam hal apapun.

2. Pengelolaan dilakukan secara demokratis, setiaap anggota koperasi mempunyai hak bebas berpendapat, namun harus mempunyai aturan yang jelas yakni sesuai dengan prinsip koperasi.

3. Pembagian SHU dilakukan secara adil, SHU merupakan pendapatan koperasi yang diperoleh dalam satu tahun buku dikurangi biaya, penyusutan lainnya termasuk pajak dalam tahun buku yang bersangkutan.

4. Kemandirian, koperasi ini dapat berdiri sendiritanpa tergantung pada pihak koperasi lain dapat diartikan juga sebagai kebebasan yang bertanggung jawab.

\section{PENUTUP}

\section{KESIMPULAN}

Dari hasil lapangan tentang pengawasan, pengawasan sangat penting dilakukan dalam koperasi agar tidak terjadi hal-hal yang tidak diingikan dalam langkah-langkah pengawasan kita dapat mengetahui perencanaan yang telah ditetapkan sebelumnya, maka dari itu dapat dilihat apakah pelaksanaan pekerjaan sesuai atau tidak dengan perencanaan tersebut, maka dapat dilihat pula penyimpangan-penyimpangan atau permasalahan yang terjadi pada pelaksanaan pekerjaan, jika terjadi penyimpangan atau permasalahan maka segera di tindak lanjuti atau dikendalikan.

\section{REFERENSI}

Adianto, Redno. 1994 Warga Belajar. Skripsi Pendidikan Luarsekolah. Tidak Untuk di Terbitkan.

Alwi, Hasan. 2005. Pengertian Profil. Jakarta: Balai Pustaka.

Bratanata, Pengertian Pendidikan . Bandung: NV. Masamaru., 1988.

Callaway, Archibald. (2012). Pendidikan Luar Sekolah. Terjemahan: Soeheba K., Jakarta: Bharata Karya Aksara dan Paris:JJnesco. 
Danim, Sudarwan. 2002. Menjadi Penelitian Kualitatif. Bandung : Pustaka Setia.

http://pengertiankomplit.blogspot.com/2016/11/pengertian-program-paket-setara-sd.html.

http://text-id.123dok.com/documentasi/definisi-warga-belajar.html.

https://visiuniversal.blogspot.com/2018/02/pengertian-sanggar-kegiatan-belajar-skb.html.

http:/pengamen/com/2007/10 diakses pada agustus 2018.

Kristiana,(2009).Pengertian Mengamen.Bandung: Remaja.

Mulyani, sri(1983:1).Pengertian Profil.Yogyakarta.

Moleong,Lexy.2002.Metodelogi Pendidikan Kualitatif. Bandung: PT. Remaja Rosdakarya.

Nasution, S.(1988). Metode Penelitian Kualitatif. Bandung : Tarsito

Neufeld, Victoria (ed). 2009.Pengertian Profil. New York: Mac Millan USA.

Peraturan Menteri. 2013. Pengertian Kesetaraan Paket A. Pendidikan dan Kebudayaan R.I nomor 81 .

Republik Indonesia (2003). Undang-undang Sistem Pendidikan Nasional.No. 20 tahun 2003.

PERWAL 2017. Konsep Sanggar Kegiatan Belajar.NO.26 tahun 2017.

Purwanto, Hadi. 2008. Sanggar Kegiatan Belajar. Yogyakarta.

Wisnu dalam Tissa (2018). Pengertian Mengamen.Skripsi Pendidikan Luarsekolah.Tidak Untuk di Terbitkan.

Setyaningsih, Dwi. 2010. Program Kesetaraan Paket A. Bandung.

Sudjana, D. (2000). Pendidikan Non Formal.Bandung : Falah Production.

Sugiyono. 2006. Metode Penelitian Kualitatif. Bandung :Alfabet.

Sugiyono.2017.MetodePenelitian Kualitatif.Bandung : Alfbabet.

Uyo, Sadulloh. 2003.Pendidikan Nasional. Bandung : PT Alfabeta. Bandung. 